\title{
Chinese Adolescents' Struggle in Online Compulsory Education during the COVID-19 Pandemic: A Foucauldian Perspective
}

\author{
Jindong Liu ${ }^{1} \cdot$ Biying $\mathrm{Wu}^{1} \mathbb{1} \cdot$ Jiayu $\mathrm{Qu}{ }^{1}$
}

Received: 4 May 2021 / Accepted: 20 July 2021/Published online: 2 August 2021

(C) The Author(s), under exclusive licence to Springer Science+Business Media, LLC, part of Springer Nature 2021, corrected publication 2022

\begin{abstract}
To tackle the debate surrounding the tension between knowledge and power in online education for adolescents and between freedom and control at large, this study examines how disciplinary power was exercised and resisted in a Chinese setting of online compulsory education during the COVID-19 outbreak in 2020. Overall, 60 participants, including students (from Grade 7 to 12), their parents, and teachers joined in our focus groups or individual interviews in a secondary school in Xi'an, China. By following Foucault's concepts of three techniques of disciplinary power: hierarchical observation, normalizing judgement and examination, we identified four themes based on the data: (1) diminished discipline with the dissolving boundary, (2) reconfigured disciplinary power by teachers, (3) self-discipline as a vital skill, and (4) online compulsory education as a future trend. Interpretations from the Foucauldian perspective were presented, suggesting that most adolescents depend upon more external disciplines from schools and teachers, while only a few may achieve autonomy through self-discipline.
\end{abstract}

Keywords Discipline and resistance - Online compulsory education - Foucault . Covid-19 - China

In contemporary studies on information and communication technologies (ICTs), one of the major debates relates to whether or not Internet can enable more freedom, autonomy, democratization and decentralization of power (Benkler, 2006; Castells, 2011; Morozov, 2012; Parks \& Mukherjee, 2017). Empowered by digital media, online education as an emerging field of practice has also participated in this debate (Carr-Chellman et al., 2000; Wood \& Fassett, 2003). Several studies

Biying Wu

biyingwu@link.cuhk.edu.hk

1 School of Journalism and Communication, The Chinese University of Hong Kong, G008, Humanities Building, New Asia College, Shatin, NT, Hong Kong SAR, China 
have investigated the tension between power and knowledge in online education through the Foucauldian lens (e.g., Gourlay, 2015; Kitto, 2003; Lee, 2020, 2021; Nicoll, 2008; Ovetz, 2017; Pham \& Duong, 2020). However, limited to the context of higher education, the current research omits the context of compulsory education that normally involves not only the underage adolescents but also much broader citizens' attendance than higher education (UN General \& Assembly, 1966).

Admittedly, online education had scarcely been exercised at a compulsory educational level. Nevertheless, it was dramatically changed by the worldwide outbreak of COVID-19. Following the restricted lockdown policies launched in many countries, real-time online course has worked as a major solution for educational institutions to sustain their teaching activities. It may be the first time in human history for compulsory education to almost totally go digitalized. According to the United Nations report (2020), 1.6 billion learners in 190 countries have been affected and driven to gain new digital literacy for dealing this new challenge in 2020. With the growing and ongoing impact of COVID-19 outbreak worldwide, we presume that the exercise of online teaching would not be merely an ephemeral moment but an opportunity for the vast and fast diffusion and development of online education at the level of compulsory education.

This emerging social phenomenon raises our interest in studying a particular research question: how is disciplinary power practiced and resisted in online education on a compulsory secondary level? Through this study, we aim to examine not only the tension between knowledge and power in online compulsory education, but also a broader debate regarding the constant changing tension between freedom and control enabled by the digital media. It matters not only for our current society but also for our next generation: understanding the way of how adolescents might be educated and disciplined in a growing digital society in the future.

\section{Autonomy and Discipline: Foucauldian views for Online Education}

The tension between self-autonomy and control remains one of the key debates in new media research nowadays (Benkler, 2006; Castells, 2011; Morozov, 2012). This debate is followed by the discussion regarding the tension between knowledge and power in the fast-developing field of online education. A number of studies have discussed this topic from a Foucauldian perspective (e.g., Gourlay, 2015; Kitto, 2003; Lee, 2020; Nicoll \& Fejes, 2008; Ovetz, 2017; Pham \& Duong, 2020). According to Lee (2020), with his influential work Discipline and Punish (1977), Foucault is one of the most frequently cited scholars in educational research and his popularity continues in the branch of online education studies. Gourlay (2015) uses Foucault's concepts to argue that online technologies enable open education, allowing people to escape from the repressive and hierarchical institutional disciplines by traditional universities. In this sense, online education works as a heterotopia of desire, playing a democratizing role for learning practices. According to Lee (2008), online education also exposed the tension between "the massification of educational production and the individualization of pedagogical processes and outcomes" (p.34). As a result, online learning can contribute to the achievement of "truth" and "emancipation" (Nicoll \& Fejes, 2008), allowing 
individuals to concentrate on the essence of learning in acquiring knowledge itself. Without the interference of institutional and bureaucratic power, online learning helps humans to be reflective and self-autonomous as a means of being free from social conditions and constraining relations (Gustavsson, 2002).

On the other hand, the relationship between online education and traditional offline education is actually more complex than the over-simplified and idealized vision of open education (Gourlay, 2015). In fact, Foucault (1990) asserts that power is not always harmful for only repressing and limiting individuals. Instead, power could also be positive and productive for people's lives. Nicoll (2008) also questions why autonomy is assumed as unquestionably good for online learning in previous literature. According to Gorbunovs et al. (2016), although the virtues of self-autonomy are essential for online learning, such skills are under-developed, especially for underage people (Kendall \& Wilcox, 1979). It caused a research gap to be filled: although the exercise of disciplinary power has been studied in online education from the Foucauldian perspective by several studies (Gourlay, 2015; Kitto, 2003; Lee, 2020; Nicoll \& Fejes, 2008; Ovetz, 2017), almost all of them only cover the context of higher education instead of compulsory education. The latter is considerably different from the former, including teaching underaged students with longer study sessions and more diverse subjects than adults, which may lead to very different learning experiences. Therefore, to fill the gap regarding the contextual differences, we wonder how institutional discipline works for students' learning outcomes in online compulsory education?

Moreover, we are interested in how students may resist against the disciplines in our context: an inevitable clash between self-autonomy and institutional discipline under the COVID-19. Lee (2020) argues that the idea of heterotopia coined by Gourlay (2015) also reflects that people need alternative space for education when they have no access to mainstream education such as normal universities or schools. The dichotomy between mainstream and online education denotes a tension between normality and abnormality in a Foucauldian sense (Lee, 2020). Whereas, in our case that compulsory education was forced to transform to online education due to the COVID-19 pandemic. There was an interesting unification between the mainstream space and heterotopia, which had led to a collision between institutional power and learners' will. According to Foucault (1990), "Power is everywhere and always is accompanied by resistance; therefore, resistance is everywhere (p.95)." We are interested in how students may react and resist the inevitable discipline from their school during the online learning sessions under the COVID-19 pandemic. In short, through a Foucauldian lens, we ask how disciplinary power is practiced and resisted in online education at a compulsory educational level. In the following part, a conceptualization of Foucauldian disciplinary power will be presented.

\section{Explicating Disciplinary Power and Its Three Techniques}

Disciplinary power is a mechanism of power for the regulation and control of the behavior of populations in a social body (Foucault, 1977). It is exercised by regulating the organization of space, time and people's activities and behaviors. According 
to Foucault (1977), there are three major techniques of control that depict the picture of modern disciplinary society: hierarchical observation, normalizing judgment, and examination.

\section{Hierarchical Observation}

Hierarchical observation refers to the omniscient presence of power and insidious monitor by means of "surveillance", which means a top-down gaze from authority and bureaucracy in a hierarchical nature (Kitto, 2003). Foucault uses Bentham's "Panopticon" to illustrate a paradigmatic architectural model of modern disciplinary power, especially about how hierarchical observation works: a round prison building with a central tower surrounded by transparent cells, which makes prisoners' every action visible and guards themselves invisible. In consequence, guards' continual surveillance disciplined prisoners to follow the certain norms. Foucault (1977) points out that the principle of the "Panopticon" can also be applied to schools. In a physical classroom, teachers can function as "guards" in the "Panopticon" who conduct surveillance on students via direct face-to-face gaze and discipline them to produce docile bodies (Ball, 2013).

When the entire school moves online, the practices of surveillance may also change accordingly. Some studies suggest the observers lose more control compared to face-to-face conditions. For example, lack of non-verbal communication with students (e.g., observing visual cues on students' faces) makes teachers feel alienated and have less control over their teaching quality (Hawkins et al., 2012), since the physical boundary of school that serves as the function of enforcing control is dissolved online (Lee, 2012). Nevertheless, Kitto (2003) argues that the principle of "Panopticon" remains effective in the online education setting. He suggests that online educational technologies work as the panoptic techniques with diverse functions which allow teachers to exercise all the disciplinary techniques. Other studies (Means et al., 2014; Morgan, 2015) also find that the introduction of new implementations and technologies enhances teachers' power of surveillance (e.g., webcams). In the context of online compulsory education, we seek to revisit how the hierarchical observation changed.

\section{Normalizing Judgement}

Normalizing judgement is a "complementary disciplinary technique that does not simply seek to repress but operates interdependently with hierarchical observation to normalize the collective" (Kitto, 2003, p. 4). In Foucault's (1977) words, normalizing is a process of imposing sophisticated norms. It involves the comparison, differentiation, measurement, hierarchization to build the value of abilities, level, and "nature" of individuals. Instead of judging the action by law, normalizing judgement aims to construct and reconstruct the criteria for people to judge what is "normal" and "abnormal". It reveals the initial function of modern disciplinary systems: the correction of deviant behaviors. Compared to the old method of power exercised 
through revenge and judicial punishment, the contemporary way of disciplinary power aims at achieving reform of people's behaviors by society's norms and social control.

In the context of online compulsory education, the question may come as "what becomes normal and abnormal when schools are moved online?" In comparison to traditional face-to-face teaching, a direct change resides in their dependency on the mediation of online educational technologies. We wonder if it could nourish new norms which challenge the school system's old norms based on classroom facilities. According to Van Dijck (2013), norms in the digital space are not necessarily equivalent to the long-established social norms in the offline context and are always in flux. Moreover, as our context is a forced practice of online education in response to the public health crisis, we need to consider how such compulsory status impacts the process of normalization. Considering two major characteristics of compulsory education, underage students and nationwide citizens' attendance, we raised two initial concerns from the perspective of media studies:

Firstly, underage students are more likely to have higher internet dependency (Ye et al., 2018), which may cause several physical and mental health problems, such as vision impairment (CNNIC, 2020), increases of depression and anxiety (Li \& Lin, 2016), decreases of attention span (Baumgartner et al., 2014), sleep disturbance and neck stiffness (Kwon et al., 2013). As a result, it might weaken students' cognitive capability to effectively handle their academic work (Barber, 1997; Baumgartner et al., 2014; Jia, 2012). Therefore, underage students are normally discouraged from using digital devices for a long time. However, the norm of compulsory education requires students to have long study sessions and heavy homework load, especially in China (Yuan et al., 2017). It may create a conflict between two norms when compulsory education encounters the internet.

Secondly, with the broad community involved in compulsory education, the normalization of online compulsory education might encounter the problem of digital divide. Existing literature has suggested that the digital divide has been a crucial issue in impeding the development of online education on a larger scale (Haythornthwaite, 2007; Palvia et al., 2018), especially for students with a low-income background (United Nations, 2020). Van Dijk (2006) defines digital divide as the gap in people's unequal access to digital technologies. By "access", he means not only physical access but also usage/skills access. Students as "digital natives" may have higher digital literacy in skills and usage than teachers and parents who are "digital immigrants" (Prensky, 2001; Underwood, 2007). Therefore, we suspect students, teachers, and parents may experience not only the physical access problems such as lack of devices or internet connectivity but also skills/usage access problems such as gaps in digital literacy.

\section{Examination}

Examination, which is to qualify, classify and categorize individuals under surveillance, is not a totally distinctive technique but an integration of hierarchical observation and normalizing judgment (Foucault, 1977). Examination aims to constitute 
individuality. The thorough information of individuals is recorded via constant exams to be the footstone of a larger power system in controlling them. In the context of education, according to Hoskin (1979), examinations have been a vital daily educational practice for modern schooling, which includes not only formal exams but also daily homework, attendance records, and relevant documents on students' personal information. Schools require them to take examinations for not only the evaluation and records of their learning outcomes and academic performances as the long-term surveillance, but also the constant normalization by classifying them with good and bad marks, convincing them how to distinguish and preserve right answers from wrong answers, and good performance from bad performance, the normal from the abnormal. Consequently, a docile body of a good student is expected to be produced through this process.

The resistance in examination often relates to students' cheating and dishonest behaviors (Llamas, 2006; McCabe et al., 1999). Such behaviors could destroy the constitution of individuality as cheating and plagiarism mean people make use of others' power to complete an independent test. Cheating in online exams has been identified as a major problem in online education practices (Kitto, 2003; Morgan, 2015). The lack of supervision leads to open-book behaviors, collaborations via SNSs (e.g., WhatsApp), and exam agents cheating (Herdian et al., 2021). As such, lecturers often found their students often achieved higher grades beyond their actual ability online (Kitto, 2003). According to Balderas and Caballero-Hernández (2020), during the COVID-19, university supervisors are more concerned about how to prevent academic dishonesty than how actually to measure students' learning outcome in online courses.

Based on existing literature (e.g., Kitto, 2003; Terblanche \& Waghid, 2020), these three techniques can be used as the framework to analyze the educational practices for explicating the tension between power and knowledge.

\section{Method}

To uncover the veil of online compulsory education, the study combined focus groups $(N=7)$ with students (5 or 6 students each group, totally $N=37)$ and in-depth interviews with teachers $(N=13)$, and students' parents $(N=10)$ in a secondary school from Grade 7 to Grade 12 in Xi' an, China from 2 to 10 June. We chose secondary school instead of primary school because they were supposed to have a richer experience in online compulsory education due to higher workload. This study was approved by the Survey and Behavioral Research Ethics Committee (SBREC) at a local university and strictly followed the principle of protecting underage participants' rights and privacy during the data collection process. A consent form that informs the purposes of the study and the rights of participants was signed by each participant before each focus group or interview was conducted. To protect students' rights as underage participants, we requested additional approval from the middle school principal on behalf of their guardians when they were at the campus. All focus groups with students were conducted on the campus during working hours. School tutors invited volunteers among 
their students to join our focus group and did not show up during the whole focus group process to guarantee a free atmosphere for students to express any opinions.

A combination of open and closed questions was used to study their attitudes towards online education. For example, "Do you think that teachers could manage the class well in the online teaching environment and why?"; "Compared to offline school teaching, what advantages and disadvantages does online teaching have?". Moreover, as secondary schools in China gradually resumed offline teaching activities since April 2020 with the gradual control of COVID-19 nationwide, this study also examined their attitude towards offline teaching compared to online teaching during the pandemic.

Both researchers made detailed notes on site and integrated notes into commonly agreed transcripts in Chinese Mandarin afterward. The transcripts were uploaded into a qualitative data analysis software Dedoose (Version, 2017). Researchers firstly applied a provisional coding in the exploratory coding method and then develop an initial code list based on the three techniques of disciplinary power stated in the literature review (Saldaña, 2015). Meanwhile, to prevent the distortion of preconceptions, we were constantly revising, improving, and developing the codebook with our familiarization with the transcripts (Saldaña, 2015). After all researchers made a consensus on the codebook, we conducted the thematic analysis with the help of the analysis functions offered by Dedoose. By checking the code presence, application, and co-occurrence, the researchers categorized the codes and identified the key themes. In the end, the researchers translated them into English in an understandable manner. All three researchers are bilingual in both Chinese Mandarin and English and aim to transmit the messages as neutral and objective as possible (Temple \& Young, 2004). For those Chinese context-specific expressions, the original Mandarin pinyin expression with English explanation is presented.

The preliminary data found that among 37 student participants, 24 of them used phones, 19 used desktops for more than $8 \mathrm{~h}$ a day to access the internet. No students reported difficulties in lack of devices, although few mentioned unstable internet connections. Most of them reported grade drops and performed lower academic results during online education. The average grade for online learning satisfaction is 6.0 out of 10. Most teachers are over 40 years old, teaching at home using their computers. Overall, teachers graded 6 out of 10 for online and 8.7 out of 10 for offline teaching satisfaction. Parents graded 5.2 out of 10 for online learning satisfaction and 8.7 out of 10 for offline. QQ live streaming is their main e-learning platform, which is one of the most popular e-learning platforms in China during the epidemic (The Cover, 2020). Based on the systematic analysis, we have identified and agreed upon four recurring themes: (1) diminished discipline with the dissolving boundary, (2) reconfigured disciplinary power by teachers, (3) self-discipline as a vital skill, and (4) online compulsory education as future trend. Next, we will present them and Interpret them from the Foucauldian perspective. 


\section{Findings}

\subsection{Theme 1. Diminished Discipline with The Dissolving Boundary}

Secondary schools used to set a boundary serving the function of enforcing control between teachers and students (Lee, 2012). However, the boundary was significantly dissolved in the e-learning environment, resulting in diminished discipline, which means that teachers' disciplinary power was greatly weakened by students, parents, and the e-learning environment. Meanwhile, the e-learning environment empowered students' rebellion against the discipline, even though their resistance remained in a superficial manner and constrained by larger social power structures. The prominence of this issue can be observed in the exercises of three techniques of disciplinary power, by forms of (1) transition in hierarchical observation, (2) colliding norms for normalizing judgement, and (3) lack of supervision in examinations.

For the exercise of hierarchical observation, teachers not only lost observing powers but also were restricted by external observers such as parents and platforms. Forty-one out of sixty respondents identified teachers' lack of surveillance, twentytwo participants stated that students were often absent or doing other things during the course sessions. As the school we visited did not require students to turn on their cameras and microphones, teachers could not monitor student's learning progress synchronically during the online class. Consistent with the extant literature (Hawkins et al., 2012; Lee, 2012; Morgan, 2015), several teachers reported that they could not judge students' instant learning feedback and modify their teaching progress correspondingly, which reduced their teaching effectiveness. Amy, a Geography teacher, made an ironic comment to show their powerlessness during the online teaching, "You can't even tell others are people or dogs in an online classroom." It was consistent with a famous adage in the early internet that denoted the characteristics of anonymity: "On the internet, nobody knows you're a dog (Steiner, 1993)."

With such anonymity empowered by e-learning platforms, teachers lost more control over students. Although teachers wished to restore their surveillance by asking students to turn on the cameras and microphones, they often encountered students' rejections with the excuse of device or technical problems such as "no microphones on the computer" or "poor internet connection", indicating students' subjective resistance to teachers' observation. Even if all students could turn on their cameras, it was still difficult to monitor all students' activities from more than 50 floating windows in a large online classroom interface. Students reported they sometimes pretended to watch, but in fact chatted with others or played games on the same screen. An extreme case of students' resistance via anonymity was reported by Sean, a Chinese literature teacher. An anonymous student disguised himself as Sean by changing his online profile and viciously cursed Sean and other students in the chatroom without identification. Such rebellious behaviors made Sean worry about the loss of his power and authority among students.

In addition, teachers' power is constrained online by the observation from other levels of the hierarchy, such as the e-learning platform and parents. Teachers from Politics and Biology experienced censorship from the platforms. Maron, 
a Politics teacher, mentioned that her exam paper, including the sensitive political keyword- "Chairman" could not be transmitted on the QQ platform. He claimed that the teaching content strictly followed the textbook and political correctness and used to work well in their offline teaching. Owan, a biology teacher also found her speech related to sexual terms such as "semen" would trigger the platform censorship against pornography. Relevant news reports also confirmed it was a common phenomenon in online education practices nationwide (Liu \& Sun, 2020), which could attribute to the strict internet surveillance and censorship in China (MacKinnon, 2009). Nevertheless, teachers only blamed the wrong standards of censorship set by platforms and still supported the legitimacy of state censorship, maybe because teachers in public middle schools have already been disciplined to follow the government official ideology (Zhao, 1998).

Moreover, parents who accompanied their students during the online class were also watching teachers' performances. Hanna, a Grade 8 Biology teacher, mentioned that she was careful with criticizing students due to the possible presence of parents. Sisi, a mother of a Grade 7 student, noticed that teachers might act more cautiously in discussing extra topics beyond textbooks. According to Mann and Ferenbok (2013), in contrast to top-down "surveillance", the powerless can also conduct bottom-up "sousveillance" (referring to their undersight) on the powerful people through rising video streaming tools in this digital age. It has radically changed the power politics in protests and social movements (Thorburn, 2014), which also have intruded the domain of education when platforms join the game. Overall, the hierarchical relationships in the "classroom" were further expanded, not only involving the teacher-student relations but also teachers' relationship with parents, with the platform, and the state. With the constraint from more external hierarchical observations, teachers' disciplinary power was further limited.

Concerning the normalizing judgement, our two initial concerns have been confirmed. For the negative aspects of internet dependency, the secondary education norms of long-time offline study sessions were inherently consistent but relatively adjusted to an extent in the online education setting. It suggested a process of normalization of online compulsory education: long-time learning sessions on digital devices became a normal requirement for anyone involved. Most course schedules required equal length of study time in online and offline conditions, except for the courses that were not suitable for online teaching, such as physical exercise or crafting classes.

On the other hand, the previous norm of "a ban on digital devices" on campus was inevitably abandoned because students were required to use their phones or laptops for at least $7 \mathrm{~h}$ reported by thirty-four out of thirty-seven students. Most students and teachers reported their physical health damages as the side effects of overuse, such as backache, vision impairment, and attention span decline, consistent with existing literature (Baumgartner et al., 2014; CNNIC, 2020). To cope with the adverse outcomes caused by the continuation of the original norm, schools had to reduce workload and study sessions to prevent the overuse of digital technology, though it was less effective than expected. The reduced workload on both teachers and students further weakened teachers' disciplinary power. 
On the issue of the digital divide in the process of normalization, although there was no notable case related to the physical access divide since our sample was collected from a modern and developed city, a clear usage/skill divide was found between senior teachers (more than 40 years old) and students or young teachers. According to 25 teachers and students' claims, senior teachers were not good at using e-learning platforms and often encountered technical accidents. By comparison, most students and young teachers could master digital skills quickly. Many students even taught old teachers regarding the technical skills in reverse. Several young teachers further explored new digital tools to enhance their teaching qualities, such as the simultaneous use of the writing pads or smartphone video streaming to refashion the blackboard notes writing in the online setting. It indicates a process of normalization and construction of new norms for online compulsory education: adequate digital literacy becomes a normal requirement for teachers in online teaching. For those who cannot handle, they would be gradually judged as abnormal and deviant.

For examination, the major issue that teachers experienced was their difficulties in collecting and revising homework as well as supervising exams. Several respondents described teachers' extra efforts in collecting homework in response to the dropping rate of student homework submission, such as calls for submission every half an hour in the evening. Moreover, most teachers expressed their difficulties in grading and revising homework. Digital versions of student homework (usually photocopies of paperwork) were unfriendly for teachers to read and correct, as most teachers relied on the small and unclear smartphone touchscreens to view. Considering these difficulties, some teachers reduced and even canceled their homework, or just graded their homework not seriously. Moreover, the frequency of exams also largely decreased and even vanished. It is mainly attributed to the difficulties of systematically preventing students from cheating and plagiarism. Both students and teachers reported several cases of students' exam cheating. It freed students from the pressure of constant evaluation, classification, and documentation in the norms set by the school.

In general, the e-learning environment greatly reshaped the power relations between teachers and students from the perspective of transition in hierarchical observation, changing normalizing judgement and diminishing examination. Secondary schools used to set a boundary serving the function of enforcing control between teachers and students (Lee, 2012). However, the boundary greatly dissolved in the e-learning environment with the absence of face-to-face communication, resulting in the diminished discipline. Not just the "guard" role of teachers, but also the whole power system of school became dysfunctional. With the decline of teachers' disciplinary power, students gained more freedom, autonomy, and power for resistance or rebellion.

However, it did not lead to a happy ending for students. Based on our co-occurrence analysis, students' low satisfaction with their online learning outcomes $(6 / 10)$ mostly was related to the diminished discipline. Most respondents also reported a huge decline in their academic performances. Although students obtained to-somedegree freedom and autonomy, most of them did not make good use of such opportunities. The autonomy that Gustavsson (2002) argues for is about self-motivation: 
people deciding what to learn and how to learn, instead of playing games and chatting when teachers cannot supervise. Lily, a Grade 8 Physics teacher and a class tutor, expressed her disappointment towards her students regarding lack of motivation for study.

To be honest, one significant advantage of online education for students is the abundant knowledge and learning resources on the Internet, such as some popular science videos on Tiktok, (they are) very illustrative for students to understand Physics. I sometimes shared these videos with them, but many of them were not interested in that. They and their parents are very realistic and utilitarian, only wish to improve their grades, enter good universities and find good jobs. They don't really care about gaining knowledge (Lily).

Lily's words reflected the idea of open education and "emancipation" that we discussed before (Gourlay, 2015; Gustavsson, 2002; Nicoll \& Fejes, 2008). However, as she said, most students did not take this opportunity of active learning. Thus, we argue that they only gain freedom and autonomy increased in a superficial manner, practicing in an anarchic way. They were still constrained by the larger invisible "Panopticon" set by the educational system and society. Seeing from the interviews, the grade was always the priority mentioned by no matter students, parents, or teachers. Students seldom mentioned they used their free time to develop their interests. It perhaps attributes to the current education situation in China that university and high school entrance exams ("gaokao"/高考 and “zhongkao"/中考 in Chinese) are their top priority. It may also be related to the Confucian culture in Chinese education that stresses the "official learning" rather than "private learning" and the political contribution of education (Yao \& Yao, 2000). The classic Confucianism piece Lun Yu suggests "a good official should learn, and a good learner should be an official" ("仕 而优则学, 学而优则仕” in Mandarin). This view constructs the purpose of learning towards the utilitarian usage for career and social development. Students, along with their parents and teachers, still have to play the game of "compulsory education" even in the online setting. The game has one simple but clear rule: Grade.

\subsection{Theme 2 Reconfigured Disciplinary Power by teachers}

To restore and improve teachers' teaching effectiveness and students' learning outcomes, teachers have several attempts to reconfigure their disciplinary power. Although most attempts did not achieve adequate results or even failed, some representative or unique methods are worthwhile to be mentioned. The methods include extending gaze for hierarchical observation, normalizing school norms of a serious and regulated offline classroom in the unserious online setting, and rebuilding the individuality of students in the examination.

To improve teachers' hierarchical observation, teachers have developed their power through parents' and peers' extending gaze. Nineteen respondents reported teachers' requirements or suggestions of parents' participation in online class to supervise their children. Laura, a class tutor, organized parents into different teams and delegated certain parents as team leaders to supervise other parents' performance. Most teachers confirmed the effectiveness of such parent-to-child 
surveillance. Nevertheless, not all parents were able to manage their children effectively, not only because of being occupied by their works but also because of students' extended resistance against their parents' observation in the form of teenage rebellion, reported by six respondents. Moreover, four respondents reported teachers delegated certain well-performed students to be team leaders to supervise other team members on behalf of the teachers. Sisi reported her child's English teacher used this way to organize their English reading sessions and received favorable outcomes to some extent. Each team had their small online group chatroom, and the teacher would randomly check a couple of teams each time. By assigning certain students and parents to be the middle-level managers as the "eyes" of teachers, teachers enriched the hierarchy of observation in the online setting.

For normalizing judgement, teachers rebuilt and normalized the seriousness and rules of the offline classroom environment in the online setting. It could be seen as an invasion of physical school norms into the social media norms. For example, it used to be normal for Chinese teenagers to use memes in online group chats as a part of their youth culture (Szablewicz, 2014). A few young teachers who understood the youth culture may also join the use of memes. However, most older teachers did not understand the meaning of memes, especially some obscure ones. To avoid the "impolite and improper" manner, the use of memes, emoji, and net slangs was prohibited by many teachers to create a "pure and clean" study environment. Lily even used a silence function in the online chatroom to silence and remove students who misbehaved and disobeyed. She said, "After being removed, students have to make a formal statement of apology and promise to me if they want to rejoin. This technique works well because they feel anxious about being excluded from the group." It can be the analogy of physical punishment that some teachers used at school: Punish students who misbehaved to leave the classroom.

To improve teachers' disciplinary power in examinations, the core strategy is to restore the individuality of students in the tests. One way to restore individuality was the clear and detailed documentation of homework submission records. Sean applied such daily documentation to accumulate the "sins" of students who refused homework submissions. Sean said, "although my 'whip' is too far to reach them right now, I warned and even threatened them that I would 'clear the debt' based on their misbehavior record after the epidemic." Consequently, the homework submission rate in Sean's class was much better than other classes. According to Foucault (1977), the documentation has the constant and continuous power in controlling the subjects. As discussed above, students may escape for a moment but cannot escape forever in the light of the continuous documentation in the system of larger social "Panopticon". The second way to achieve individuality is to isolate students during the test. For example, when Sean checked students' individual poem recitations, she demanded students to turn on cameras and close their eyes. It was a reverse live video streaming to force students to be isolated and complete the test independently. In some online exams, parents' participation was also effective in isolating students and preventing plagiarism from the perspective of hierarchical observation. However, despite the effectiveness, these strategies are time-consuming that may not be suitable for broader popularization. For example, the normal checking time for Sean's poem recitation homework was $3 \mathrm{~h}$ per day. 
In short, a few attempts were made to restore teachers' disciplinary power among students by extending gaze with parents' and peers' help, imposing more school norms of serious and regulated study environment, and restoring individuality of students during the exams. However, we need to acknowledge that these attempts remained limited or unstable because of some parents' unavailability and time-consuming execution of exam supervisions. Teachers' reconfiguration of power still has a long way to go.

\subsection{Theme 3 Self-Discipline as a Vital Skill}

Despite the poor performances of most students and the dedication of teachers in restoring discipline, we also found that some students' academic performances were generally steady or even improved during the online learning period. Through their experiences, we identified the third theme: self-discipline. In consistent with the existing literature examining university students (e.g., Gorbunovs et al., 2016; Kitto, 2003), we also found that self-discipline is of importance in achieving a positive learning outcome in an online learning environment for secondary school students. In our case, ten out of thirty-seven students reported to be less affected by the diminished discipline in the online environment, most of their academic performance were in the top $10 \%$, and four of them were even in the top $1 \%$ among their peers. We found that those students had a higher sense of awareness of their academic performances and competitiveness with other classmates. One Grade 12 student said, "I was anxious all the time. I felt my classmates were always studying. I couldn't relax and had to study too." Hence, they were usually more willing to interact with teachers, set their own timetable, and do extra homework.

Their behaviors could be regarded as the result of self-discipline, which is relative to disciplinary power, but more relevant to the idea of "biopower" coined by Foucault (1977). Pylypa (1998) explains Foucault's biopower as "the ways in which power manifests itself in the form of daily practices and routines through which individuals engage in self-surveillance and self-discipline, and thereby subjugate themselves (p.21)." It means that individuals voluntarily control themselves by self-imposing conformity to discourses and cultural norms. Hence, we argue that they are better "players" in the game of compulsory education, as the most disciplined individuals in the established educational and social system. On the other hand, through their examples, we also see the possibility of genuinely embracing freedom and autonomy as a learner, though only reported by one student. As top $1 \%$ in the Grade, the student shared his joyful experience of attending various free online lectures on popular science and humanities, which are new public resources open for the whole society emerging during the pandemic. He was also one of the minorities who preferred online education to offline. His example meets the expectation for an ideal learner claimed by Lily, Gourlay (2015), and Gustavsson (2002): a self-motivated individual who is truly curious about knowledge and embraces open education.

Nevertheless, the exercise of self-discipline is not necessarily contradictory to the significance of disciplinary power from teachers for most students, as the trait 
of self-discipline can only be found in a very small number of top students. These top students may have already been "self-disciplined" students before online teaching. In fact, they also reported their need for external discipline and regarded it as a more powerful than self-discipline, let alone other average students. Admittedly, it is common for underage teenagers to choose playing rather than learning (Hughes, 2009). Culturally speaking, according to Benedict (2005) and Fung (1999), social orders and morality in the Oriental societies such as China and Japan are likely to be developed through "shame culture". In those societies, people may need external concerns from the public and watched to be disciplined. Although Confucianism also highlights the importance of self-discipline (Chaibong, 2001), it is thoroughly practiced through external disciplines and heteronomy (Jung, 1993). Therefore, the external discipline is still indispensable.

\subsection{Theme 4 Online Compulsory Education as A Future Trend}

Overall, we saw a high inadaptability of participants to deal with the e-learning platforms. Still, many of them stressed the irreplaceability of face-to-face teaching and deemed online compulsory education as an ephemeral phenomenon. However, many teachers reported their continuous use of e-learning technologies in their current offline teaching activities. They believed it would be the trend due to its advantages in overcoming the spatial and temporal limits. Lee, a Grade 11 Math teacher whose class mainly consisted of elite students, stated his use of online platforms to organize small-size tutorials for a few top students. He claimed that it could overcome the spatial limits of offline teaching to achieve the personalization and precision of education, which will be the future trend of compulsory schooling. Lee said: "Different students have different learning capabilities. It is less effective to teach everyone with the same content and speed. Cyberspace offers a space for me to teach top students with extra knowledge." Hans, a grade-10 Chemistry teacher, also pointed out the advantages of online teaching in overcoming time constraints. Through the recording and archiving of learning materials and tests, it can constantly benefit students at all academic performance levels in the long term. These claims are congruent with Gourlay (2015) and Lee (2008) who argue that online education can help the democratization of education and individualization of learning process and outcomes.

Following such a trend, a process of normalization is still ongoing. On the one hand, online educational technologies normalized teachers and students on the issues of surveillance, physical/skills access, and examinations. On the other hand, teachers and students were also normalizing online educational technologies with the demand for better learning and teaching experience. Typical examples include the growing connection speed and stability, more functions for homework collection, and revision provided by e-learning platforms to fulfill users' demands. Meanwhile, several teachers were calling for access to more advanced personal digital tools (e.g., writing pad) for online education purchased and distributed by the school to further boost the teaching effectiveness. Some teachers were also expecting the establishment of non-commercial online education platforms by official sectors in 
response to the advertisements and content not suitable for teenagers (e.g., sex and violence) on commercial online education and live streaming platforms.

In short, although offline education has its irreplaceable status compared to online education, this study sees online compulsory education not as an ephemeral phenomenon caused by the public health crisis. Instead, it is a future trend for the combination of online and offline education to promote the personalization of education in the future. Accordingly, an infrastructurization of online education will be developed through the digitalization and platformization of compulsory education, which also indicates the institutionalization of online education on a national level, reinforcing the larger "Panopticon" of educational system and society.

\section{Conclusion}

This article examines how disciplinary power is exercised and resisted in an online education platform at the compulsory educational level in the case of Chinese secondary school during the COVID-19 pandemic. Based on a systematic analysis, we identified four themes: (1) diminished discipline with the dissolving boundary, (2) reconfigured disciplinary power by teachers, (3) self-discipline as a vital skill, and (4) online compulsory education as a future trend.

Theme 1 and 2 were analyzed by following the Foucauldian conceptual framework of three disciplinary techniques, aiming to examine how disciplinary power is practiced and resisted in online compulsory education. We found that the e-learning environment greatly reshaped the power relations between teachers and students with the increasing resistance of students and powerlessness of teachers. Although teachers made several attempts to reconfigure their disciplinary power with the assistance of parents, peers, and platforms, some attempts were limited and less effective. Theme 3 and 4 aim to resolve the tension relations by identifying self-discipline as the vital skill and a future trend for online compulsory education. In response to the broader debate on knowledge and power or freedom and control, we found that students obtained more freedom to some degree but not truly escaped from the larger social norms set by compulsory education. The panoptic boundary of school may temporarily dissolve, but the more extensive "Panopticon" established by the society still constantly disciplines students, parents, and teachers. With the pressure from university and high school entrance examinations, the grade remained at the center of their concerns, outweighing the knowledge acquisition. As such, discipline and control from teachers, with the assistance from their peers, parents, and technologies, still played a vital role in students' academic development.

Admittedly, few self-disciplined "good players" can be both the best spokespersons of an existing power system of schools and the potential truly autonomous learners to acquire their interested knowledge freely. However, it may be unrealistic to expect all students to be like them. With the gradual development and institutionalization of the online compulsory education system, the tension between freedom and control may need constant reevaluation.

There are several limitations of this study. First, our findings might bias on the digital divide issue as the school we chose is in the urban area (Xi' an). Reported 
from our sample, most of them were in or above the middle-class economic status families. In comparison, an adolescent in a rural area was reported to commit suicide due to a lack of mobile phones to take online courses (Zhuang, 2020). Such grievous news calls for further studies focusing on suburban and rural areas. More differences in a broader sense might be found across different social and regional settings, the educational platform uses and the student's general academic results. Schools in other regions and countries that use other platforms (e.g., Zoom, DingTalk; The Cover, 2020) should be studied in the future. Moreover, some findings may be context-specific. Future research should be conducted under different social and educational systems. Despite these limitations, we argued for a contribution to the online education field. Although offline education has its irreplaceable status, we believe that online compulsory education is not an ephemeral phenomenon. Instead, it will continue to exist as not only a constant emergency mechanism in response to disasters or extreme climates (e.g., epidemic, air pollution, typhoon), but also the daily supplement of offline teaching activities to lead a new trend at the compulsory educational level.

Acknowledgements We would like to thank Ms. Qian Ouyang and Xi'an No.89 Middle School for their valuable help in data collection. We are grateful to all valuable comments provided from two anonymous reviewers.

\section{Declarations}

Disclosure statement The authors declare that they have no conflict of interest.

\section{References}

Balderas, A., \& Caballero-Hernández, J. A. (2020). Analysis of Learning Records to Detect Student Cheating on Online Exams: Case Study during COVID-19 Pandemic. In Eighth International Conference on Technological Ecosystems for Enhancing Multiculturality (pp. 752-757). https://doi.org/ $10.1145 / 3434780.3436662$.

Ball, S. J. (2013). Foucault and education: Discipline and knowledge. Routledge.

Barber, A. (1997). Net's educational value questioned. USA Today, 4.

Baumgartner, S., Weeda, W., van der Heijden, L., \& Huizinga, M. (2014). The Relationship Between Media Multitasking and Executive Function in Early Adolescents. The Journal of Early Adolescence, 34(8), 1120-1144. https://doi.org/10.1177/0272431614523133

Benedict, R. (2005). Patterns of culture (Vol. 8). Houghton Mifflin Harcourt.

Benkler, Y. (2006). The wealth of networks: How social production transforms markets and freedom. Yale University Press.

Carr-Chellman, A. A., Fitzpatrick, S., \& Zhang, K. (2000). The rhetoric of democracy in international on-line education. Information, Communication \& Society, 3(3), 289-302. https://doi.org/10.1080/ 13691180051033171

Castells, M. (2011). The rise of the network society (Vol. 12). Wiley.

Chaibong, H. (2001). Confucian rituals and the technology of the self: A Foucaultian interpretation. Philosophy East and West, 315-324.

CNNIC. (2020). 2019 National report of internet usage among minors. [2019 年全国未成年人互联网使 用情况硎究报告] Retrieved 17 June 2020, from http://www.cac.gov.cn/2020-05/13/c_1590919071 365700.htm.

Foucault, M. (1977). Discipline and Punish: The Birth of a Prison. Vintage.

Foucault, M. (1990). The history of sexuality: An introduction. Vintage. 
Fung, H. (1999). Becoming a moral child: The socialization of shame among young Chinese children. Ethos, 27(2), 180-209.

Gorbunovs, A., Kapenieks, A., \& Cakula, S. (2016). Self-discipline as a key indicator to improve learning outcomes in e-learning environment. Procedia-Social and Behavioral Sciences, 231, 256-262. https://doi.org/10.1016/j.sbspro.2016.09.100

Gourlay, L. (2015). Open education as a 'heterotopia of desire.' Learning, Media and Technology, 40(3), 310-327. https://doi.org/10.1080/17439884.2015.1029941

Gustavsson, I. (2002). Remote laboratory experiments in electrical engineering education. In Proceedings of the fourth IEEE international caracas conference on devices, circuits and systems (Cat. No. 02TH8611) (pp. I025-I025). IEEE.

Hawkins, A., Barbour, M. K., \& Graham, C. R. (2012). "Everybody is their own island": Teacher disconnection in a virtual school. The International Review of Research in Open and Distributed Learning, 13(2), 124-144. https://doi.org/10.19173/irrodl.v13i2.967

Haythornthwaite, C. (2007). Digital divide and e-learning. The Sage handbook of e-learning research, 97-118.

Herdian, H., Mildaeni, I. N., \& Wahidah, F. R. (2021). "There are Always Ways to Cheat" Academic Dishonesty Strategies During Online Learning. Journal of Learning Theory and Methodology, 2(2), 60-67. https://doi.org/10.17309/jltm.2021.2.02

Hoskin, K. (1979). The examination, disciplinary power and rational schooling. History of Education, $8(2), 21-135$.

Hughes, F. P. (Ed.). (2009). Children, play, and development. Sage.

Jia, R. (2012). Computer playfulness, internet dependency and their relationships with online activity types and student academic performance. Journal of Behavioral Addictions, 1(2), 74-77. https://doi. org/10.1556/jba.1.2012.2.5

Jung, H. Y. (1993). Confucianism as political philosophy: A postmodern perspective. Human Studies, 16(1-2), 213-230.

Kendall, P. C., \& Wilcox, L. E. (1979). Self-control in children: Development of a rating scale. Journal of Consulting and Clinical Psychology, 47(6), 1020.

Kitto, S. (2003). Translating an Eletronic Panopticon Educational technology and the re-articulation of lecturer-student relations in online learning. Information, Communication \& Society, 6(1), 1-23. https://doi.org/10.1080/1369118032000068796

Kwon, M., Lee, J. Y., Won, W. Y., Park, J. W., Min, J. A., Hahn, C., ... \& Kim, D. J. (2013). Development and validation of a smartphone addiction scale (SAS). PloS One, 8(2), e56936. https://doi.org/10. 1371/journal.pone.0056936.

Lee, F. (2008). Technopedagogies of mass-individualization: Correspondence education in the mid twentieth century. History and Technology, 24(3), 239-253. https://doi.org/10.1080/073415108019003 18

Lee, A. Y. (2012). Online news media in the Web 2.0 era: From boundary dissolution to journalistic transformation. Chinese Journal of Communication, 5(2), 210-226. https://doi.org/10.1080/17544 750.2012 .664442

Lee, K. (2020). Michel Foucault in technology-enhanced learning: An analytic review of 10 Foucauldian studies on online education. Studies in Technology Enhanced Learning, 1(1).

Lee, K. (2021). Openness and innovation in online higher education: A historical review of the two discourses. Open Learning: THe Journal of Open, Distance and e-Learning, 36(2), 112-132. https:// doi.org/10.1080/02680513.2020.1713737

Li, L., \& Lin, T. T. (2016). Exploring work-related smartphone dependency among young working adults in China: A qualitative approach. International Journal of Communication, 10, 19.

Liu, C., \& Sun, N. (2020). China's online classes are minefield for censorship amid coronavirus. Asia Nikkei. Retrieved 17 June 2020, from https://asia.nikkei.com/Politics/China-s-online-classes-areminefield-for-censorship-amid-coronavirus.

Llamas, J. M. C. (2006). Technologies of disciplinary power in action: The norm of the 'Good student.' Higher Education, 52(4), 665-686.

MacKinnon, R. (2009). China's censorship 2.0: How companies censor bloggers. First Monday, 14(2). https://doi.org/10.5210/fm.v14i2.2378.

Mann, S., \& Ferenbok, J. (2013). New Media and the power politics of sousveillance in a surveillancedominated world. Surveillance \& Society, 11(1/2), 18-34. 
McCabe, D. L., Trevino, L. K., \& Butterfield, K. D. (1999). Academic integrity in honor code and nonhonor code environments: A qualitative investigation. The Journal of Higher Education, 70(2), 211-234.

Means, B., Bakia, M., \& Murphy, R. (2014). Learning online: What research tells us about whether, when and how. Routledge.

Morgan, H. (2015). Online Instruction and Virtual Schools for Middle and High School Students: Twenty-First-Century Fads or Progressive Teaching Methods for Today's Pupils? The Clearing House: A Journal of Educational Strategies, Issues and Ideas, 88(2), 72-76.

Morozov, E. (2012). The net delusion: The dark side of internet freedom. PublicAffairs.

Nicoll, K. (2008). Discipline and e-learning. Foucault and lifelong learning: Governing the subject, $164-177$.

Nicoll, K., \& Fejes, A. (2008). Mobilizing Foucault in studies of lifelong learning. Foucault and lifelong learning: Governing the subject, 1-18.

Ovetz, R. (2017). Click to save and return to course: online education, adjunctification, and the disciplining of academic labour. Work Organisation, Labour and Globalisation, 11(1), 48-70. https://doi. org/10.13169/workorgalaboglob.11.1.0048

Palvia, S., Aeron, P., Gupta, P., Mahapatra, D., Parida, R., Rosner, R., \& Sindhi, S. (2018). Online education: Worldwide status, challenges, trends, and implications.

Parks, L., \& Mukherjee, R. (2017). From platform jumping to self-censorship: Internet freedom, social media, and circumvention practices in Zambia. Communication and Critical/cultural Studies, 14(3), 221-237. https://doi.org/10.1080/14791420.2017.1290262

Pham, L., \& Duong, B. H. (2020). Education, globalization, and citizenship: reflections of Vietnamese local school teachers and overseas-educated academics. Discourse: Studies in the Cultural Politics of Education, 1-17. https://doi.org/10.1080/01596306.2020.1836746.

Prensky, M. (2001). Digital natives, digital immigrants. On the horizon, 9(5).

Pylypa, J. (1998). Power and bodily practice: Applying the work of Foucault to an anthropology of the body. Arizona Anthropologist, 13, 21-36.

Saldaña, J. (2015). The coding manual for qualitative researchers. Sage.

Steiner, P. (1993). On the internet, nobody knows you're a dog. The New Yorker, 69(20), 61.

Szablewicz, M. (2014). The 'losers' of China's internet: Memes as 'structures of feeling' for disillusioned young netizens. China Information, 28(2), 259-275. https://doi.org/10.1177/0920203X14531538

Temple, B., \& Young, A. (2004). Qualitative research and translation dilemmas. Qualitative Research, $4(2), 161-178$.

Terblanche, J., \& Waghid, Y. (2020). A Foucauldian analysis of the CA profession in South Africa: Implications for society. South African Journal of Higher Education, 34(1), 1-17. https://doi.org/ $10.20853 / 34-1-3893$

The Cover. (2020). Teachers and students had online courses across the country, do you know about these data? [全国师生都在上网课 这些数据你知道吗?] Sina News. Retrieved 17 June 2020, from http:// gd.sina.com.cn/news/xy/2020-04-03/detail-iimxxsth3368900.shtml.

Thorburn, E. D. (2014). Social media, subjectivity, and surveillance: Moving on from occupy, the rise of live streaming video. Communication and Critical/cultural Studies, 11(1), 52-63. https://doi.org/10. 1080/14791420.2013.827356

Underwood, J. D. (2007). Rethinking the Digital Divide: Impacts on student-tutor relationships. European Journal of Education, 42(2), 213-222. https://doi.org/10.1111/j.1465-3435.2007.00298.x

UN General Assembly. (1966). International Covenant on Economic, Social and Cultural Rights, United Nations, Treaty Series, vol. 993, p. 3. Retrieved from https://www.refworld.org/docid/3ae6b36c0. html.

United Nations. (2020). Policy Brief: Education during COVID-19 and beyond. Retrieved from https:// www.un.org/development/desa/dspd/wp-content/uploads/sites/22/2020/08/sg_policy_brief_covid19_and_education_august_2020.pdf.

Van Dijk, J. (2006). Digital divide research, achievements and shortcomings. Poetics, 34(4-5), 221-235. https://doi.org/10.1016/j.poetic.2006.05.004

Van Dijck, J. (2013). The culture of connectivity: A critical history of social media. Oxford University Press.

Version, D. (2017). 4.5, web application for managing, analyzing, and presenting qualitative and mixed method research data (2013). SocioCultural Research Consultants, LLC (www.dedoose.com).

Wood, A. F., \& Fassett, D. L. (2003). Remote control: Identity, power, and technology in the communication classroom. Communication Education, 52(3-4), 286-296. 
Yao, X., \& Yao, H. C. (2000). An introduction to Confucianism. Cambridge University Press.

Ye, S., Toshimore, A., \& Horita, T. (2018). The effects of personality traits on smartphone dependency and loneliness: a study of university students in Japan. Journal of Socio-Informatics, 10(1), 1-13.

Yuan, W., Zhang, L. F., \& Fu, M. (2017). Thinking styles and academic stress coping among Chinese secondary school students. Educational Psychology, 37(8), 1015-1025. https://doi.org/10.1080/ 01443410.2017 .1287343

Zhao, S. (1998). A state-led nationalism: The patriotic education campaign in post- Tiananmen China. Communist and Post-Communist Studies, 31(3), 287-302.

Zhuang, M. L. (2020). The girl without cellphone to join online classes. [没有手机上网课的少女]. News China. Retrieved 27 May 2020, from https://mp.weixin.qq.com/s/nZKJ51X-z429Xpn3hmSfDQ.

Publisher's Note Springer Nature remains neutral with regard to jurisdictional claims in published maps and institutional affiliations. 